\title{
Problems, Challenges and Benefits of Implementing E-learning in Nigerian Universities: An Empirical Study
}

\author{
doi:10.3991/ijet.v4i1.653 \\ Manir Abdullahi Kamba \\ Bayero University Kano
}

\begin{abstract}
This paper tries to examine and discuss the problems, challenges and Benefits of implementing ELearning in Nigeria by reviewing the consciousness and willingness of the selected Universities. This study also identifies the enabling factors, the traffic-jam and, forecasts the future growth of E-learning in Nigeria. Survey research method was adopted for the study, and questionnaire was the only instrument used for the data collection. The findings of the study show that out of the 18 universities selected from different specialization areas, i.e three universities from each Geopolitical zone, only 12 responded with usable answers. The response rate was $67 \%$, which is an expected rate for such surveys. Awareness of e-learning among the Universities is very high but investment and commitment to develop an e-learning application is very poor and below expectation according to the study. Most of the staff and students in the universities only use Internet related e- learning site just for the sake of finding related information for their researches, since their libraries cannot afford to provide them with adequate and current materials but not for the sake of real online learning. The study also found out that some of the universities have web page and others are in the trend of creating a web page, which is usually for advertisement of the universities but not for the e-leaning activities. Furthermore, the findings also reveal that staff and the students have also been using e-mail and Internet in addition to developing web pages for transaction of students. The Universities are planning to invest number of funds in future in the selected areas of the e-learning application. The Statistical analysis result shows that there are significant differences across both forms of e-learning activities and type of universities in Nigeria.
\end{abstract}

Index Terms-E- learning, Internet, Implementation and Nigeria.

\section{INTRODUCTION}

Modern achievements in the field of computer and communication technologies have offered tremendous opportunities for learning by electronic means (Rozina, 2002). The use of new multimedia technologies and the Internet in learning is seen as a means to improve accessibility, efficiency and quality of learning by facilitating access to resources and services as well as remote exchanges and collaboration. E-learning has become a new paradigm and a new philosophy in education with a mission to serve as a development platform for present-day society based on knowledge.
Learning in an electronic environment is great challenge in Nigeria because of so many factors. At this time due to many negative factors in the economy Nigeria could not afford broad access to all the latest achievements available for education, as well as enable new educational technologies and e-learning to be widely used in universities. Part of these negative factors included difficulties with computers and Internet access, electricity, in adequate skills; low literacy e.t.c. Today, educational sector in Nigeria witnessed critical shortage of appropriate teaching materials, very ineffective system for digital learning resources creation, storage and maintenance. The teaching corpus was untrained in the effective use of information and communication technologies in the educational process.

But today things have started to change to better because in the research carried out by Manir (2007) on the availability and utilization of the Internet found that in the nearest future educational programs by electronic means will cover from 40 to 50 percent of learning time in Nigerian universities. Positive feedback comes from data on tremendous growth of computer equipment and internet utilization by academic staff in the Nigerian universities.

It is obvious that the concept of e-learning is considered to be very attractive as a new learning paradigm whose effect will be a positive one to the development of education in developing countries especially Nigeria, with all its potentialities not much effort is taken for its implementation, present-day research of e-learning in Nigeria shows that having e-learning on the agenda Nigeria is still facing a lot of problems in this field. Many of problems and challenges are not only technologically but also socially, educationally, economically and culturally sensitive. This has been attested by Tuzlukova, (2004) in his study in Russia stating in the respect of above problems and challenges that some researchers in Russia consider that the research focus will gradually move from technology issues (means and tools) onto learning itself. For example, Tuzlukova reports on some impressions of Russian English language teachers who took an e-learning course "Integrating Internet into the Classroom". Though the course was a wonderful and a very rewarding experience and its content was relevant to teachers' needs, there were some challenges in completing it.

Additionally he further explains that the biggest challenges/obstacles for the teachers in completing the course were such as time conflict with family and work 
(teaching) commitments. Teachers also mentioned computer fatigue and physical risks (eye strain after staring at the screen for hours, sore back, chronic "pins and needles" in feet, legs). Some teachers said about a bad quality of Internet connection and difficulties accessing a computer/printer. Except lack of sufficient computer and Internet skills, insufficient experience with Internet -based teaching, lack of organizational/management support from their home universities they also mentioned a new learning style so different from the traditional Russian culture of learning (Tuzlukova, 2004).

To this extent the modern world is undergoing a fundamental transformation as the industrial society of the twentieth century rapidly gives way to the information society of the twenty-first century. This dynamic process promises a fundamental change in all aspects of our lives, including knowledge dissemination, social interaction, business practices, political engagement, media, education, health, leisure and entertainment. The speed of global technological and economic transformation demands urgent action to turn the present digital divide into digital opportunities for all. Poor access to the Internet in Nigeria is widely acknowledged by Manir (2007) Adeya and Oyeinka, (2002).

\section{LITERATURE REVIEW}

Rosenberg (2001) defines learning as "the process by which people acquire new skills or knowledge for the purpose of enhancing their performance'’. He explains that the perceptions of learning in organizations are undergoing a distinct transformation. First, training should no longer only focus on the act of training but must demonstrate a positive impact on performance or outcomes. As the world is changing the learning scenario is changing with the change in the introduction of information and communication technology, which gives room to the new concept called e-learning. In his book Rosenberg (2001) defines e-learning as a networked phenomenon allowing for instant revisions and distribution. In addition, it is delivered using standard Internet technology. E-learning goes beyond training and instruction to the delivery of information and tools to improve performance. The benefits of e-learning are many including cost-effectiveness, enhanced responsiveness to change, consistency, timely content, flexible accessibility, and providing customer value. The discussion emphasizes the need for organizations to build a strategic foundation for e-learning, addressing the emerging approaches to elearning in addition to synthesizing other learning efforts of the organization.

The advantages of e-learning must outweigh its disadvantages for its implementation to be worthwhile. Amongst the many advantages of e-learning are that it is less expensive to deliver. E-learning is self-paced, provides consistent content, faster and works anywhere and at anytime for learners. The instructional materials are easily updated and permit the use of multimedia which leads to reinforced learning through the use of video, audio, quizzes and other forms of interaction. E-learning can improve retention, provide immediate feedback and allows learners to customize learning materials to meet their individual needs (Kirsh, 2002; Turk and Robertson, 2000). E-learning provides for risk-free simulation environments for acquisition of valuables skills in fields involving leadership and decision making. The disadvantages are that it may cost more to develop and requires new skills for the production of content. The associated technology might be intimidating, at times confusing, frustrating and costly. E-learning requires on the part of the learner, more responsibility and selfdiscipline to keep up with an unconstrained and robust learning process.

According to Manir (2007) internet technologies offer extensive development opportunities, particularly for education, teaching, research and learning. Wireless Internet technologies could allow universities and institutions in developing countries to bridge the gap of information and materials access. Connecting Universities in Nigeria to the Internet will have a positive impact on education and their teaching system. The Internet complements locally available information, improves and accelerates knowledge flows, and can be used to deliver innovative education models to remote areas. There is a broader debate that comes to mind when thinking of the introduction of e-learning in the developing world like Nigeria. However, ICTs can be part of the solution. If education and capacity-building are critical steps for entering into the new global economic and educational development, e-learning should be considered a critical facet of basic development, an alternative medium of capacity-building and a means to people's empowerment. Gunawardana (2005) Computer-literacy is an imperative precondition for learners to benefit from technology-based learning. E-learning can only build on a set of basic computer literacy skills. Learners should go through an introductory session for each programme that focuses on professional development in the use of technology in the classroom.

The most effective way to make e-learning a successful experience is to keep it as simple as possible. This is particularly true from a technological perspective, as well as valid from a pedagogical perspective. One has to know how to target the audience, consisting of working adults who have limited free time and experience learning online, which, as with any distance learning, requires a lot of self-discipline and time-management skills.

Furthermore, Gunawardana (2005) highlights that studies in e-learning have shown that most programmes are likely to succeed with the constant involvement of the facilitator through e-mail discussion lists and individualized messages. The facilitator's constant involvement and feedback are the most powerful support for the learner. Many online courses consist of nothing but instructional material (unsupported web-based trainings); others provide a forum for exchange. Very sophisticated courses combine all elements of online learning in one design called "blended learning" and are the best way to create educational environments.

\section{Methodology}

Two separate research processes were implemented: a questionnaire and an interview to study the respondent's individual learning experience. The first used a hard-copy survey instrument for collecting quantitative data on practical interaction of e-learning implementation. The second was to interview a sample group of academic staff and students in universities of Nigeria, to obtain qualitative data on their own e-learning experience as well as their own understanding of factors, contributing to e- 
learning effectiveness or slowing it down. The study use 18 universities for the purpose of this studies as the sample from different specialization areas, i.e three universities from each Geopolitical zone, only 12 responded with usable answers. The study obtained 120 responses for the quantitative approach and 36 interviews for the qualitative approach.

\section{FINDINGS AND DISCUSSION}

The findings of the study show that considering the universities in Nigeria as the producer of e-learning inputs in the forms of skills in ICT, both the staff, students and the universities administration are aware of the existence and benefit of e-learning, this has the response rate of $55 \%$ of the total respondents of the study. But on the issue of implementation there is a very low response rate, which in variably shows that implementation has not be given much priority in Nigerian institutions because it has a major demand for information management systems (MIS) to track product (transcripts, courses, facilities, staff, etc.). In reality, in Nigeria, the entire operation of most universities (with the possible exception of payroll) is performed manually. Beyond its MIS demands education is expected to experience major benefits from the use of ICT for technology-enhanced-learning (TEL). TEL includes program of electronic/digital supports for distance education, to technology-enhanced classrooms, and virtual laboratories. Networked access is also seen as an efficient response to binding constraints in terms of trained instructors and classroom facilities. This is an area where the Ministry of education, NUC in Nigeria should have responsibility for universities, not only in setting policy and implementation, but also in drawing together that consortium of stakeholders whose wisdom and support will be necessary to make things work. Formulating where to start this process should be one result of a Ministry of education and Nigerian Universities Commission (NUC's) participation in a national ICT planning process.

The findings of the study exhibit that the lack of sufficient, trained ICT professional has been a recurring focus in ICT studies and reports in Nigeria. Nigeria produces only a small number of ICT-trained University graduates (high quality) each year. The number of positions in the state-funded universities is severely limited. However, the quality of training is highly variable. Nigerian universities face a serious shortage of experienced ICT professionals that could support the real e-learning implementation. Most of the staff and students do not have the adequate knowledge on how to use the elearning programme.

The study found that most of the staff and students in the universities up to $53 \%$ only use Internet related elearning site just for the sake of finding related information for their researches, since their libraries cannot afford to provide them with adequate and current materials but not for the sake of real online learning. As ICT becomes more a part of everyday life, it will be increasingly necessary for all the universities staff and students to have some basic familiarity with computers. Technology revolutions are complete when such skills are taken for granted and the technology seems to have disappeared into the background. It is easy to say .using them in the universities in Nigeria will help.
The study also found out that some of the universities have web page and others are in the trend of creating a web page, which is usually for advertisement of the universities but not for the e-leaning activities. Furthermore, the findings also reveal that staff and the students have also been using e-mail and Internet in addition to developing web pages for transaction of students. The Universities are planning to invest number of funds in future in the selected areas of the e-learning application.

On the factors affecting the successful implementation of e-learning in Nigeria are based on the following basic elements according to the findings of the study:

1) Instructional material is important. Learners take online courses more seriously if they receive material to work with: e.g., books, CD-ROMs, which also save online time.

2) Tutorial support provides motivation. Learners often need guidance and support from instructors, coaches, tutors or technical staff. However, this is also a question of costs-how much financial means an online course has.

3) Communication. Using telecommunication tools like the Internet facilitates not only the distribution of information but also the interaction between learners and instructors, as well as among learners themselves. Giving them the opportunity to hare knowledge, experience and perspectives is a central demand of instructional theories.

4) Collaboration combines the demand for social communicative learning with the instructional demand for active learning.

5) Lack of electricity supply.

6) Insufficient funds to upgrade and maintain the equipments and the facilities.

7) Lack of good policy implementation.

8) Lukewarm attitudes by the side of staff and students in the e-learning processes.

The findings of the study further found that most common encountered are issues such as unreliable Internet connection and phone lines, slow access to web sites due to narrow bandwidth and limited numbers of computers connected to the Internet. Therefore, a key challenge is that technological requirements must be kept to a minimum in order to increase the participation of Nigeria into the implementation of e-learning. Easy access to all course materials is essential. Given the technological constraints that users in developing countries have to face, asking them to download or print documents from a web site is just too much. Most of the users of the e-learning programmes do not own a computer and have Internet access only from the universities internet cafes.

\section{CONCLUSION}

For e-learning to succeed in Nigeria, it needs to build on another important pillar: the existence of infrastructure, along with some degree of connectivity. A growing difference in market liberalization of the Internet- access supply is leading to another kind of "digital divide" on the global scale many countries have introduced or are introducing telecommunications regulations that discourage the development of Internet-access service 
through competition. Moreover, other technical constraints have to be overcome. It is, therefore, fundamental to implement self-sustaining Internet and computer training, which will eventually allow universities to keep pace with developed countries and give them access to technological and academic information, as well as Internet training at various levels. The benefits they gain will thus affect every aspect of their personal and professional life.

\section{REFERENCES}

[1] Rozina I. (2002) Theory and Practice of Computer-assisted Communication in Russia: Present-day Situation and Future Perspectives. In: Theory of Communication and Applied Communication. Journal of Russian Communication Association. Issue 1

[2] Manir, A.K. (2007) Availability and Utilization of the Internet for Academic Activities in selected federal universities in Northern Nigeria. Master thesis unpublished.

[3] Tuzlukova (2004) On Some Cultural and Social Aspects of Educational Discourse in E-Medium. In: Language and Communication, Rostov-on-Don

[4] Adeya and Oyeyinka (2002) the Internet in African Universities: Case study of Kenya and Nigeria. As part of the study of infornomic an UNU/INTECH Netherlands. Available at www.google.com. Retrieved 25/10/2005.
[5] Rosenberg, M..J. (2001). E-Learning: Strategies for Delivering Knowledge in the Digital Age New York, NY: McGraw-Hill Companies, Inc.

[6] Kirsh, D. (2002), "E-learning, metacognition and visual design”, paper presented at the International Conference on Advances in Infrastructure for e-Business, e-Education, e-Science, and eMedicine on the internet, L'Aquila, Italy, 29 July-4 August

[7] Robertson, G. M.T. (2000), "Perceptual user interfaces", Communications of the ACM, Vol. 43 No.2, pp.3.

[8] Manir A.K. (2007) The Internet as tool for Interactive Learning, Teaching and Research. International Journal of Emerging Technologies in Learning. Vol.2 (3)

[9] Gunawardana (2005) An Empirical Study of potential challenges and Benefits of Implementation Proceedings of the Second International Conference on e-learning for Knowledge-Based Society, August 4-7, 2005, Bangkok, Thailand

\section{AUTHOR}

K Manir (manirung@yahoo.com) is a lecturer with Bayero University, Kano, in the Department of Library and Information Sciences, But presently a Ph. D students with the Department of Library and information sciences in International Islamic university Malaysia.

Manuscript received 08 September 2008. Published as submitted by the author. 